\title{
PLANNING PROBLEMS OF A GAMBLING-HOUSE WITH APPLICATION TO INSURANCE BUSINESS
}

\author{
HaRALD BohmaN \\ Stockholm
}

In the classical risk theory the interdependence between the security loading and the initial risk reserve is studied. It could be said that the purpose of these studies are to state how large the security loading must be in order to avoid ruin of the insurance business. It has often been said that the classical approach with an infinite planning horizon is unrealistic. The main reason for this attitude is that if the security loading is equal to zero then ruin is certain. Since in practice it is often difficult to estimate the true size of the security loading the whole problem of ruin or non-ruin seems to rest on a rather shaky foundation. This attitude to the problem is reflected in studies in risk theory performed in recent years. The infinite planning horizon is then often replaced by a finite time period. Since the probability of ruin during a short period of time depends to a minor extent on the size of the security loading these studies are concentrated mainly on the shape of the claim distribution, while the security loading is of minor interest.

Let us think of a gambling-house, where coin-tossing is practised. Let us assume that the gambling-house for reason of fairness decides to pay two dollars to each winner who has staked one dollar. Probability theory tells us that however rich the gambling-house may be, it will be ruined in the long run. This simple example reminds us of the trivial fact that insurance business without a sufficient security loading in the premium is commercially impossible.

I will here discuss the problem of profitability, solvency and risk of an insurance company in a somewhat other way than is usual done in risk theory. To make my point of view quite clear I will start by describing the problem from the point of view of a gamblinghouse.

In the gambling-house I have in mind the only type of gambling permitted is coin-tossing. The gambling-house has decided that each 
gambler is allowed to stake at most $K$ dollars per game. The gambling-house has also decided that it wants to make a certain profit on its gambling business and it has decided that in the long run this profit should amount to $P \%$ of the stakes paid by the customers. In order to achieve this goal the gambling-house pays to each winner $(200-2 P) \%$ of his stake instead of the "fair" amount $200 \%$ of the stake.

In order to define a goal the gambling-house must decide upon a planning period. Having done so the gambling-house defines its goal in the following way: At the end of the planning period the expected profit will be equal to $P \%$ of the total amount of stakes paid during the planning period. At the same time the actual profit should "very likely" be larger than zero. For the purpose of our investigation it is practical to measure the planning period by the amount of stakes paid during the period. Let us denote this amount by $N$.

Since the gambling-house must remain solvent the whole of the time it must have a risk reserve. The size of the risk reserve at the beginning of the planning period is denoted by $U$. The actual size of the risk reserve will at each time depend on the actual outcome of the games played and it is a goal of the gambling-house that the risk reserve shall never become negative.

The degree of uncertainty, which this gambling business involves for the gambling house, can be measured by the variance of the profit. It turns out that this variance is proportional to the maximum stake per game accepted by the gambling-house. By deciding upon the maximum stake per game the gambling house can thus control the variance of the business.

Summing up we have thus introduced the following concepts which are important for the gambling-house in its planning activity.

Level of profit equal to $P \%$ of stakes.

Planning period equal to $N$ dollars.

Maximum size of stake per game equal to $K$ dollars.

Initial value of risk reserve at the beginning of planning period equal to $U$ dollars.

We now find the following expressions for the expected value of the profit and the variance of the profit at the end of the planning period. 
Expected profit $=N P /$ roo

Variance $\quad=N K(\mathrm{I}-\mathrm{P} / \mathrm{IOO})^{2}$

We have here made the assumption that all gamblers use the maximum stake which is an assumption on the safe side.

According to the goal of the gambling-house the actual profit at the end of the planning period should very likely be larger than zero. As a numerical expression for this request we will choose $N$, $K$ and $P$ in such a way that the standard deviation at the end of the planning period is equal to $\mathrm{I} / 3$ of the expected profit.

As for the goal to remain solvent during the planning period it is equivalent to the problem to find out how large $U$ should be. For the numerical solution of this problem I used simulation technique. I simulated the process one thousand times, each time assuming that $U$ was equal to zero at the beginning of the planning period. Each simulation gave as a result the minimum value of $U$ during the experiment.

From among the I,000 experiments I chose the second lowest in accordance with statistical practice which says that from a number of observations you should always exclude the largest and the smallest observation before making use of the data. I then con-

\begin{tabular}{ccccr}
\hline Risk reserve & $\begin{array}{c}\text { Expected } \\
\text { profit } \\
\$\end{array}$ & $\begin{array}{c}\text { Profit } \\
\text { rate } \\
\%\end{array}$ & $\begin{array}{c}\text { Planning } \\
\text { period } \\
\$\end{array}$ & $\begin{array}{c}\text { Maximum } \\
\text { stake } \\
\$\end{array}$ \\
\hline 1,000 & 3,000 & I & 300,000 & 3.4 \\
1,000 & 3,000 & 2 & 150,000 & 6.9 \\
1,000 & 3,000 & 4 & 75,000 & 14.5 \\
1,000 & 3,000 & 8 & 37,500 & 31.5 \\
2,000 & 6,000 & 1 & 600,000 & 6.8 \\
2,000 & 6,000 & 2 & 300,000 & 13.9 \\
2,000 & 6,000 & 4 & 150,000 & 28.9 \\
2,000 & 6,000 & 8 & 75,000 & 63.0 \\
4,000 & 12,000 & I & $1,200,000$ & 13.6 \\
4,000 & 12,000 & 2 & 600,000 & 27.8 \\
4,000 & 12,000 & 4 & 300,000 & 57.9 \\
4,000 & 12,000 & 8 & 150,000 & 126.0 \\
8,000 & 24,000 & I & $2,400,000$ & 27.2 \\
8,000 & 24,000 & 2 & $1,200,000$ & 55.5 \\
8,000 & 24,000 & 4 & 600,000 & 115.7 \\
8,000 & 24,000 & 8 & 300,000 & 252.0 \\
\hline
\end{tabular}


cluded that in 999 experiments the gambling-house should have remained solvent during the whole planning period if its risk reserve at the beginning of the period had amounted to the said value. This size of $U$ will then imply that it is "very likely" that the gambling-house will remain solvent during the planning period.

Suppose for example that the risk reserve is equal to $4,000 \$$ and that the gambling-house wants $4 \%$ profit. It is seen from the table that the planning period in that case must be $300,000 \$$ and that the maximum stake per game is equal to $57.9 \$$.

Several interesting observations can be made from this table. If we keep the risk reserve constant we note that when the profit rate increases the planning period decreases, while the maximum stake increases. If the competitive situation between different gamblinghouses is such that it is advantageous to keep the profit rate low then our gambling-house should choose a long planning period and a low maximum stake.

If we keep the planning period constant we observe that if the risk reserve increases then both profit rate and maximum stake increases. Finally we observe that if the profit rate is kept constant and we wish to increase the maximum stake then both planning period and risk reserve increases.

After having discussed the planning problems of the gamblinghouse I now present a corresponding analysis of an insurance business. I produced a simulation program for insurance business. According to this program the insurance business and its development is first characterized with the aid of a number of parameters which are fed into the computer. The computer then simulates the activity of the company during the planning period and repeats this experiment one thousand times. The results of these experiments are then presented in the following way.

PLANNING HORIZON $=$ Io YEARS

PREMIUM AT BEGINNING OF PLANNING PERIOD I500

OWN CAPITAL AT BEGINNING OF PLANNING PERIOD Ioo

INTEREST $=6 \%$ PER ANNUM

COEFFICIENT OF SCEWNESS $=5.1$

PREMUM INCREASES BY $7 \%$ PER ANNUM

PROFIT LEVEL $=2 \%$ OF PREMIUM INCOME

STANDARD DEVIATION GROSS $=5 \%$ OF PREMIUM

AT BEGINNING OF PLANNING PERIOD 
STRATEGY IS THAT RISKLEVEL AS MEASURED BY THE

STANDARD DEVIATION NET SHALL BE $=15 \%$ OF

OWN CAPITAL AT MOST AND ALSO $=5 \%$ OF

PREMIUM INCOME AT MOST

OWN CAPITAL AT END OF PLANNING PERIOD WILL VERY

LIKELY BE LARGER THAN 587.0 AND LESS THAN

2813.7 WHILE MEDIAN IS 2404.7

BALANCE NET OF REINSURANCE CEDED WILL AT END OF

PLANNING PERIOD VERY LIKELY BE LARGER THAN -75.8 AND LESS THAN 0.0 WHILE MEDIAN IS 0.0

MINIMUM VALUE OF OWN CAPITAL DURING PLANNING

PERIOD WILL VERY LIKELY BE LARGER THAN 347.0

The term "Own capital" is here meant to be the same as risk reserve. The distribution function corresponding to the total amount of claims per year has a standard deviation which is equal to a certain percentage of the premium income per year and this percentage can be chosen freely. This value of the standard deviation is then valid at the beginning of the planning period. In successive years the standard deviation then increases in proportion to the square root of the premium.

The distribution function of the total amount of claims per year is a two term exponential polynomial. The parameters of this polynomial can be chosen to correspond to different values of the coefficient of scewness of the distribution.

The sentence beginning with the word "Strategy" describes the reinsurance policy of the company. In our example it is said that if the standard deviation of the total amount of claims on own account is larger than $15 \%$ of the risk reserve or larger than $5 \%$ of the yearly premium income then the portfolio must be reinsured to such an extent that the said limits are both observed. It is assumed that reinsurance takes place according to the quota share principle.

The size of the risk reserve at the end of the planning period is presented by quoting the largest value but one, the smallest value but one and also the medium value.

The net result of reinsurance ceded is quoted similarly. A negative balance corresponds to a loss of the ceding company.

The minimum value of the risk reserve during the planning period is equal to the smallest value but one among the I,000 observations. 